\title{
Is Plant Nitrogen Depletion Really Linked to the Biosynthesis of Carbon-Rich Defense-Related Compounds in Organic Products?
}

\author{
Simona Fabroni* and Paolo Rapisarda \\ Council for Agricultural Research and Economics (CREA), Research Center for Olive, \\ Fruit and Citrus Crops, Acireale (CT), Italy \\ *Corresponding Author: Simona Fabroni, Council for Agricultural Research and \\ Economics (CREA), Research Center for Olive, Fruit and Citrus Crops, Acireale (CT), \\ Italy.
}

Previous studies speculated on the existence of an inverse relationship between the available nitrogen and the accumulation of defense-related secondary metabolites in plants [1], as a consequence of C:N ratio unbalance. According to this hypothesis, the lower nitrogen contents of organically grown plants lead to a shift from the N-containing compounds to the production of carbonrich defense-related phenylpropanoids. It has been also suggested that this behavior is putatively linked to the increased resilience to pest attacks and damage exerted by organic plants [2-4]. Recent research [5] showed that long-term organic fields have been associated with no consistent difference in nitrogen and carbon content, nor in C:N ratio, between the organic and conventional produces. In parallel, pest attacks were preferentially settled on conventional plants respect to organic ones. Organic management reduced insect population but no evidence about plant nutrient unbalance was directly linked with. The study demonstrated that organic soil management promoted salicylic acid build-up, which resulted in discouraging plant-insect interactions. Indeed, salicylic acid accumulation was not associated with lower nitrogen content of organic plants but it depended on alterations in soil microbial communities associated with long-term organic management. The study showed that over-presence of specific microbial groups induced plant resistance to pest attacks. By this way, it can be postulated that organic practices promotes plant resistance through derived changes in soil microflora.

Several studies have shown that organically grown fruit are richer in antioxidants compared with conventionally grown fruit [6-12]. In accordance with the higher antioxidant values of organic products, the systematic review by Baranski., et al. [13], based on an extensive dataset of 343 peer-reviewed publications, showed that organic crops have higher concentrations of polyphenolics and other antioxidants together with a higher antioxidant activity. Since many years, the theory according to which nitrogen deficiency may induce the production of carbon-rich phenylpropanoids has been postulated as an explanation of the higher healthy value of organic products. Based on recent experimental evidence reported on how soil microbiota influences plant resistance to pests, it may also be hypothesized that polyphenolics may accumulate in organic plant due to functional shifts in soil microflora. Further in depth and rigorous studies are needed to better understand how the organic management promote beneficial microbial populations and which are the biochemical mechanisms underlying induced organic plant defense $[14,15]$.

\section{Bibliography}

1. Brandt K., et al. "Agroecosystem management and nutritional quality of plant foods: the case of organic fruits and vegetables". Critical Reviews in Plant Sciences 30 (2011): 177-197.

2. Drinkwater L., et al. "Fundamental differences between conventional and organic tomato agroecosystems in California". Ecological Applications 5 (1995): 1098-1112.

3. Mattson WJ. "Herbivory in relation to plant nitrogen content". Annual Review of Ecology and Systematics 11 (1980): 119-161.

4. Megali L., et al. "Fertilization with beneficial microorganisms decreases tomato defenses against insect pests". Agronomy for Sustainable Development 34 (2014): 649-656.

5. Robert Blundell., et al. "Organic management promotes natural pest control through altered plant resistance to insects". Nature Plants 6 (2020): 483-491. 
6. Lester G., et al. “Organic vs conventionally grown rio red whole grapefruit and juice: comparison of production inputs, market quality, consumer acceptance, and human health-bioactive compounds". Journal of Agricultural and Food Chemistry 55 (2007): 4474-4480.

7. Navarro P., et al. "Antioxidant activity, color, carotenoids composition, minerals, vitamin $\mathrm{C}$ and sensory quality of organic and conventional mandarin juice, cv. Orogrande". Food Science and Technology International 17 (2011): 241-248.

8. Rapisarda P., et al. "Nitrogen metabolism components as a tool to discriminate between organic and conventional citrus fruits". Journal of Agricultural and Food Chemistry 53 (2005): 2664-2669.

9. Esch JR., et al. "Determination of the vitamin c content of conventionally and organically grown fruits by cyclic voltammetry". International Journal of Electrochemical Science 5 (2010): 1464-1474.

10. Rapisarda P., et al. "The Influence of Different Organic Fertilizers on Quality Parameters and the $\delta^{15} \mathrm{~N}, \delta^{13} \mathrm{C}, \delta^{2} \mathrm{H}, \delta^{34} \mathrm{~S}$ and $\delta^{18} \mathrm{O}$ Values of Orange Fruit (Citrus sinensis L. Osbeck)". Journal of Agricultural and Food Chemistry 58 (2010): 3502-3506.

11. Camin F., et al. "Potential isotopic and chemical markers for characterizing organic fruits". Food Chemistry 125 (2011): 1072-1082.

12. Chebrolu KK., et al. "Production system and storage temperature influence grapefruit vitamin c, limonoids, and carotenoids". Journal of Agricultural and Food Chemistry 60 (2012): 7096-7103.

13. Baranski M., et al. "Higher antioxidant and lower cadmium concentrations and lower incidence of pesticide residues in organically grown crops: a systematic literature review and meta-analyses". British Journal of Nutrition 112 (2012): 794811.

14. Crowder DW., et al. "Organic agriculture promotes evenness and natural pest control”. Nature 466 (2010): 109-112.

15. Lichtenberg EM., et al. "A global synthesis of the effects of diversified farming systems on arthropod diversity within fields and across agricultural landscapes". Global Change Biology 23 (2017): 4946-4957.

\section{Assets from publication with us}

- Prompt Acknowledgement after receiving the article

- Thorough Double blinded peer review

- Rapid Publication

- Issue of Publication Certificate

- High visibility of your Published work

Website: www.actascientific.com/

Submit Article: www.actascientific.com/submission.php

Email us: editor@actascientific.com

Contact us: +919182824667 